\title{
Reduced 5-FU clearance in a patient with low DPD activity due to heterozygosity for a mutant allele of the DPYD gene
}

\author{
JG Maring*,', ABP van Kuilenburg², J Haasjes², H Piersma ${ }^{3}$, HJM Groen ${ }^{4}$, DRA Uges ${ }^{5}$, AH Van Gennip ${ }^{2}$ and \\ EGE De Vries ${ }^{6}$ \\ 'Department of Pharmacy, Diaconessen Hospital, Meppel and Bethesda Hospital, Hoogeveen, Hoogeveenseweg 38,7943 KA Meppel, The Netherlands; \\ ${ }^{2}$ Department of Clinical Chemistry, Academic Medical Center and Emma Children's Hospital, University of Amsterdam, Meibergdreef 9 , I I 05 AZ \\ Amsterdam, The Netherlands; ${ }^{3}$ Department of Internal Medicine, Martini Hospital, Van Swietenlaan 4, 9728 NZ Groningen, The Netherlands; \\ ${ }^{4}$ Department of Pulmonary Medicine, University Hospital, Hanzeplein 1, 9713 GZ Groningen, The Netherlands; ${ }^{5}$ Department of Pharmacy, University \\ Hospital, Hanzeplein I, 9713 GZ Groningen, The Netherlands; ${ }^{6}$ Department of Medical Oncology, University Hospital, Hanzeplein I, 97 I 3 GZ \\ Groningen, The Netherlands
}

5-fluorouracil pharmacokinetics, dihydropyrimidine dehydrogenase-activity and DNA sequence analysis were compared between a patient with extreme 5-fluorouracil induced toxicity and six control patients with normal 5-fluorouracil related symptoms. Patients were treated for colorectal cancer and received chemotherapy consisting of leucovorin $20 \mathrm{mg} \mathrm{m}^{-2}$ plus 5 -fluorouracil $425 \mathrm{mg} \mathrm{m}^{-2}$. Blood sampling was carried out on day I of the first cycle. The 5-fluorouracil area under the curve $_{0 \rightarrow 3 \mathrm{~h}}$ in the index patient was $24.1 \mathrm{mg} \mathrm{h} \mathrm{I}{ }^{-1}$ compared to $9.8 \pm 3.6$ (range $5.4-15.3$ ) $\mathrm{mg} \mathrm{h} \mathrm{I}^{-1}$ in control patients. The 5 -fluorouracil clearance was $520 \mathrm{ml} \mathrm{min}^{-1}$ vs $1293 \pm 302$ (range $\left.980-1780\right) \mathrm{ml} \mathrm{min}^{-1}$ in controls. The activity of

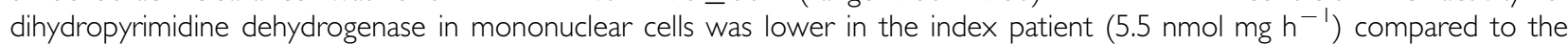
six controls $\left(10.3 \pm 1.6\right.$, range $\left.8.0-11.7 \mathrm{nmol} \mathrm{mg} \mathrm{h}^{-1}\right)$. Sequence analysis of the dihydropyrimidine dehydrogenase gene revealed that the index patient was heterozygous for a IVSI4+IG>A point mutation. Our results indicate that the inactivation of one dihydropyrimidine dehydrogenase allele can result in a strong reduction in 5-fluorouracil clearance, causing severe 5-fluorouracil induced toxicity.

British Journal of Cancer (2002) 86, 1028 - 1033. DOl: 10.1038/sj/bjc/6600208 www.bjcancer.com

(C) 2002 Cancer Research UK

Keywords: DPD; 5-fluorouracil; pharmacokinetics; DPYD gene; mutation; pharmacogenetics

Fluorouracil (5-FU) is widely used in chemotherapeutic regimens for the treatment of breast-, colorectal- and head- and neck cancer. The cytotoxic mechanism of 5-FU is complex, requiring intracellular bioconversion of 5-FU into cytotoxic nucleotides (see Figure 1). Inhibition of thymidylate synthase by the metabolite 5 -fluoro- $2^{\prime}$ deoxyuridine- $5^{\prime}$-monophosphate is thought to be the main mechanism of cytotoxicity (Pinedo and Peters, 1988). The cytotoxicity is caused by only a small part of the administered 5-FU dose, as the majority of 5-FU is rapidly metabolised into inactive metabolites. The initial and rate-limiting enzyme in the catabolism of 5-FU is dihydropyrimidine dehydrogenase (DPD), catalysing the reduction of 5-FU into 5,6-dihydrofluorouracil (DHFU). Several groups have suggested a major role of DPD in the regulation of 5 -FU metabolism and thus in the amount of 5-FU available for cytotoxicity (Harris et al, 1990; Fleming et al, 1992a; Lu et al, 1993; Etienne et al, 1994). Indeed, in patients with DPD enzyme deficiency, 5-FU chemotherapy is associated with severe, life-threatening toxicity (Van Kuilenburg et al, 2000a). Moreover, a markedly prolonged elimination half-life of 5-FU has been observed in a patient with complete deficiency of DPD enzyme

*Correspondence: JG Maring; Department of Pharmacy, Diaconessen Hospital, PO Box 502, 7940 AM Meppel, The Netherlands;

E-mail: maring@diacmeppel.nl

Received 6 July 200I; revised 31 December 200I; accepted 22 January 2002 activity (Diasio et al, 1988). Several mutations in the dihydropyrimidine dehydrogenase gene (DPYD), which encodes for the DPD enzyme have recently been identified (Van Kuilenburg et al, 2000a; Collie-Duguid et al, 2000). Furthermore, the frequency of DPD deficiency has been estimated to be as high as $2-3 \%$ (Etienne et al, 1994; Lu et al, 1995; Chazal et al, 1996). To date, a direct correlation between DPYD gene mutation and decreased 5-FU clearance has only been suggested but never been proven. In this study, we provide the first detailed analysis of 5-FU pharmacokinetics in a patient with low DPD-activity due to heterozygosity for a mutant allele of the gene encoding DPD.

\section{METHODS}

\section{Chemicals}

5-Fluorouracil was obtained from Sigma Chemical Co. (Zwijndrecht, The Netherlands). 5,6-Dihydro-5-fluorouracil was kindly provided by Roche Laboratories (Basel, Switzerland). AmpliTaq Taq polymerase and BigDye-Terminator-Cycle-Sequencing-ReadyReaction kit were supplied by Perkin Elmer (San Jose, CA, USA). A Quaquik Gel Extraction kit was obtained from Qiagen (Hilden, Germany). Human heparinised plasma was obtained from the Red Cross Blood Bank (Groningen, The Netherlands). $\left[4-{ }^{14} \mathrm{C}\right]$ Thymine $\left(1.85-2.22 \mathrm{GBq} \mathrm{mmol}^{-1}\right)$ was obtained from Moravek Biochemicals (CA, USA) and Lymphoprep (spec.gravity $1.077 \mathrm{~g} \mathrm{ml}^{-1}$, 280 mOsm) was from Nycomed Pharma AS (Oslo, Norway). 


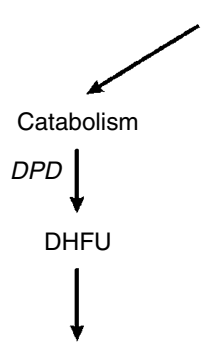

$5-\mathrm{FU}$

FUPA

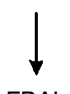

FBAL

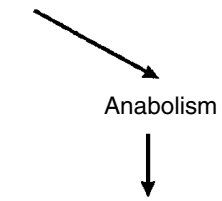

Nucleotides/Nucleosides

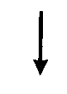

FdUMP

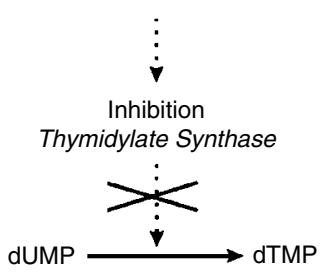

Figure I Metabolism of 5-FU. 5-Fluoro-2'-deoxyuridine-5'-monophosphate (FdUMP) is the cytotoxic product resulting from a multi-step 5-FU activation route. FdUMP inhibits the enzyme thymidylate synthase (TS), which leads to intracellular accumulation of deoxy-uridine-monophospate (dUMP) and depletion of deoxy-thymidine-monophosphate (dTMP). This causes arrest of DNA synthesis. The initial and rate-limiting enzyme in the catabolism of 5-FU is dihydropyrimidine dehydrogenase (DPD), catalysing the reduction of 5-FU into 5,6-dihydrofluorouracil (DHFU). Subsequently, DHFU is degraded into fluoro- $\beta$-ureidopropionic acid (FUPA) and fluoro- $\beta$-alanine (FBAL).

Leucosep tubes were supplied by Greiner (Frickenhausen, Germany). All other chemicals were of analytical grade.

\section{Patient and controls}

All patients were treated for Dukes $\mathrm{C}$ colorectal cancer and participated in a protocol that had been designed to study 5-FU and DHFU pharmacokinetics. The protocol was approved by the Medical Ethics Review Committee of the Martini Hospital Groningen and written informed consent was obtained from all patients. All patients who entered this protocol were chemotherapy naive. Chemotherapy consisted of leucovorin $20 \mathrm{mg} \mathrm{m}^{-2}$ combined with 5 -FU $425 \mathrm{mg} \mathrm{m}^{-2}$, both on 5 successive days, in a 28 -day cycle. Blood sampling was carried out on the first day of the first chemotherapy cycle immediately following the 5-FU dose, administered as bolus intravenous injection over 2 min. Leucovorin was infused after the end of blood sampling. On the following 4 days, the same 5-FU dose was administered as short time infusion, after leucovorin administration. One patient experienced severe toxicity during the first chemotherapy cycle and, therefore, a screening on DPD deficiency was initiated. Data from six patients who participated in the same study protocol and who showed no signs of severe toxicity were randomly selected for reference pharmacokinetics, DPYD genotyping and DPD enzyme activity. These patients served as controls.

\section{Collection of blood samples}

For pharmacokinetic sampling, a canule was placed in the arm of the patient contralateral from drug administration. Blood samples $(5 \mathrm{ml})$ were collected in heparinised tubes just before, and 2, 5, $10,20,30,45,60,80,100,120,150$ and $180 \mathrm{~min}$ postinjection. Collected samples were immediately placed on ice and subsequently centrifuged at $2500 \mathrm{~g}$ for $10 \mathrm{~min}$. The plasma samples were analysed for 5-FU and DHFU concentrations by high-performance liquid chromatography (HPLC) on the day of collection. Blood samples for DPD analysis were collected 5 to 23 months after blood sampling for 5-FU pharmacokinetics, which corresponds to intervals ranging from 2 to 17 months after the last 5-FU dose. None of the patients received chemotherapy at that moment.

\section{Reversed phase HPLC analysis}

5-Fluorouracil and DHFU concentrations were measured by HPLC analysis using a modification of the method described by Ackland et al (1997). Briefly, $100 \mu \mathrm{l}$ chlorouracil internal standard solution $\left(80 \mathrm{mg} \mathrm{l}^{-1}\right.$ in water) was added to $1 \mathrm{ml}$ plasma sample, and this mixture was vortexed and subsequently deproteinated with $50 \mu \mathrm{l}$ of a $50 \%\left(\mathrm{w} \mathrm{v}^{-1}\right)$ trichloracetic acid solution. After centrifugation at $8000 \mathrm{~g}$ for $2 \mathrm{~min}$ the supernatant was transferred into a $20 \mathrm{ml}$ centrifuge tube and neutralised with $1 \mathrm{ml} 1 \mathrm{M}$ sodium acetate solution. Then $5 \mathrm{ml}$ ethylacetate was added and the mixture was vortexed during $10 \mathrm{~min}$. After separation of the organic and aqueous layers by centrifugation at $5000 \mathrm{~g}$ for $5 \mathrm{~min}$, the ethylacetate layer was transferred into a $10 \mathrm{ml}$ tube and evaporated under a stream of nitrogen at $25^{\circ} \mathrm{C}$. The residue was dissolved in $100 \mu \mathrm{l}$ ultrapure water and $20 \mu \mathrm{l}$ was injected. 5-Fluorouracil and DHFU standards ranging from 0.5 to $20 \mathrm{mg} \mathrm{l}^{-1}$ were prepared in human plasma. The chromatographic system consisted of a Waters 616 pump equipped with a Waters $717+$ autosampler. The separation of 5-FU and DHFU was accomplished by gradient elution at ambient temperature on a Phenomenex Prodigy ODS 3 column (I.D. $250 \times 4.6 \mathrm{~mm}, 5 \mu \mathrm{m})$ equipped with a guard column $(30 \times 4.6$ $\mathrm{mm}$ ) of the same material. Mobile phase A consisted of $1.5 \mathrm{~mm}$ $\mathrm{K}_{3} \mathrm{PO}_{4}$ and $1 \%\left(\mathrm{v} \mathrm{v}^{-1}\right)$ methanol $(\mathrm{pH}=6.0)$ and mobile phase $\mathrm{B}$ of $1.5 \mathrm{mM} \mathrm{K}_{3} \mathrm{PO}_{4}$ and $5 \%\left(\mathrm{v} \mathrm{v}^{-1}\right)$ methanol $(\mathrm{pH}=6.0)$.

The gradient was programmed as follows: $100 \%$ A during $2 \mathrm{~min}$; $100 \% \mathrm{~A} \rightarrow 100 \% \mathrm{~B}$ in $0.5 \mathrm{~min} ; 100 \% \mathrm{~B}$ during $7 \mathrm{~min} ; 100 \%$ $\mathrm{B} \rightarrow 100 \% \mathrm{~A}$ in $0.5 \mathrm{~min} ; 100 \% \mathrm{~A}$ during $10 \mathrm{~min}$. Detection was performed using a Waters 996 Photo Diode Array UV detector interfaced with a Millenium 2010 Chromatography Manager Workstation. Spectra were acquired in the 201-300 nm range. 5FU was monitored at $266 \mathrm{~nm}$ and DHFU at $205 \mathrm{~nm}$. The internal standard chlorouracil was monitored at both wavelengths.

\section{Pharmacokinetic analysis}

The pharmacokinetic analyses were performed in the ADAPT II computer program (version 4.0; USC Los Angeles). The pharmacokinetic data of both the index patient and the six control patients were tested in eight different models. In each model the patient's data were fitted individually and for each data set the Akaike Information Criterion (AIC) was calculated. The model with the lowest summarised AIC value was selected as the better one (data not shown). The model used for calculating 5-Fluorouracil pharmacokinetics is a two-compartment model with Michaelis-Menten elimination from the first compartment and is described by two differential equations:

$$
\begin{gathered}
\frac{d X_{1}}{d t}=\left(\frac{V_{\max }}{V_{1} k_{\mathrm{m}}+X_{1}}+k_{12}+k_{\text {urine }}\right) X_{1}+k_{21} X_{2}+R_{\mathrm{inf}} \\
\frac{d X_{2}}{d t}=k_{12} X_{1} \quad k_{21} X_{2}
\end{gathered}
$$

$X_{1}$ and $X_{2}$ indicate the amount of drug in each compartment, respectively. The $k$-values represent linear distribution- and elimination rate constants, and the $V_{\max }$ and $K_{\mathrm{m}}$ values represent Michaelis-Menten constants for non-linear elimination from the first compartment. $R_{\text {inf }}$ represents the infusion rate of 5-FU.

The area under the curve of 5-FU and DHFU was calculated using the trapezoid rule. The average systemic clearance of 5-FU was calculated by dividing the administered dose by the area under the curve $\left(\mathrm{AUC}_{0} \rightarrow{ }_{3 \mathrm{~h}}\right)$. 


\section{Determination of dihydropyrimidine dehydrogenase activity}

To investigate whether the 5-FU toxicity might have been caused by a partial deficiency of DPD, we determined the activity of DPD in peripheral blood mononuclear (PBM) cells. Therefore PBM cells were isolated from $15 \mathrm{ml}$ EDTA anticoagulated blood and the activity of DPD was determined according previously described methods (Van Kuilenburg et al, 2000b). In brief, the sample was incubated in a reaction mixture containing $35 \mathrm{~mm}$ potassium phosphate $\mathrm{pH} 7.4,1 \mathrm{~mm}$ dithiothreitol, $2.5 \mathrm{~mm}$ magnesium chloride, $250 \mu \mathrm{M}$ NADPH and $25 \mu \mathrm{M}\left[4{ }^{-14} \mathrm{C}\right]$ thymine. After an appropriate incubation time, the reaction catalysed by DPD was terminated by adding $10 \%\left(\mathrm{v} \mathrm{v}^{-1}\right)$ perchloric acid. The reaction mixture was centrifuged at $11000 \mathrm{~g}$ for $5 \mathrm{~min}$ to remove protein. The separation of radiolabelled thymine and the reaction products was performed by reversed phase HPLC. Protein concentrations were determined with a copper-reduction method using bicinchoninic acid, as described by Smith et al (1985).

\section{PCR amplification of coding exons}

The DNA from the index and control patients was isolated from PBM cells as previously described (Van Kuilenburg et al, 1997). PCR amplification of exon 14 and flanking intronic regions was carried out according to Van Kuilenburg et al (2000a). PCR products were separated on $1 \%$ agarose gels, visualised with ethidium bromide and purified using a Qiaquick Gel Extraction kit and used for direct sequencing.

\section{Sequence analysis}

Sequence analysis of the genomic fragment was carried out on an Applied Biosystems model 377 automated DNA sequencer using the Dye-Terminator method.

\section{Statistical analysis}

Each value, measured in the index patient, was compared to the mean \pm 2 s.d. range of the corresponding parameter in the control group. Values outside this range were considered abnormal $(P<0.05)$. We did not match our control patients for age and gender.

\section{RESULTS}

\section{Clinical evaluation}

Patient characteristics from the index and control patients, as measured before 5-FU administration on the first day of the first chemotherapy cycle, are listed in Table 1 . The index patient is a 60 -year-old white female who received adjuvant chemotherapy for Dukes C colon carcinoma. She was known with a chronic moderate renal function impairment as a result of a double-sided nephrolithotomy at age 40. The first two injections with a total dose of $800 \mathrm{mg} 5$-FU day $^{-1}$ were tolerated well by the patient without complications. On the third day of chemotherapy she experienced nausea and cold shivers. The nausea was successfully treated with metoclopramide. The cold shivers remained on days 4 and 5. Twelve days after administration of the first 5-fluouracil injection, leukopenia $\left(1.5 \times 10^{9}\right.$ leukocytes $\left.1^{-1}\right)$ and thrombocytopenia $\left(26 \times 10^{9}\right.$ platelets $\left.1^{-1}\right)$ developed along with nausea, diarrhoea, stomatitis, fever and hair loss. The next day leukocytes and platelets decreased to $0.5 \times 10^{9} 1^{-1}$ and $12 \times 10^{9} 1^{-1}$ (both nadir values respectively). During this period the patient developed leukopenic fever $\left(40^{\circ} \mathrm{C}\right)$ for which antibiotics were administered. Until day 20 the leucocytes and platelets remained low $\left(1 \times 10^{9} 1^{-1}\right.$ and $13 \times 10^{9} 1^{-1}$ respectively). During the subsequent week the clinical picture and hematological parameters gradually improved and normalised. On day 34 the patient was discharged from the hospital.

The toxicity observed in the six control patients was limited to mild nausea $(n=4)$, vomiting $(n=2)$ and CTC grade 1 stomatitis $(n=1)$.

\section{Pharmacokinetic analysis}

The clearance of 5-FU was considerable slower in the index patient than in the six control patients. In all control patients the plasma level at $t=90 \mathrm{~min}$ was below $0.1 \mathrm{mg} \mathrm{l}^{-1}$, whereas in the index patient the plasma level was still $3.8 \mathrm{mg} \mathrm{l}^{-1}$ at this time point (see Figure 2). The $\mathrm{AUC}_{0} \rightarrow_{3 \mathrm{~h}}$ in the patient suffering from toxicity was $24.1 \mathrm{mg} \mathrm{h} \mathrm{l}^{-1}$ compared to $15.3 \mathrm{mg} \mathrm{h} \mathrm{l}^{-1}$ as highest $\mathrm{AUC}_{0} \rightarrow_{3 \mathrm{~h}}$ value in control patients. We calculated an average systemic clearance of only $520 \mathrm{ml} \mathrm{min}^{-1}$ vs $980-1780 \mathrm{ml} \mathrm{min}^{-1}$ in controls. The $V_{\max }$ value, calculated by pharmacokinetic modelling was $548 \mathrm{mg} \mathrm{h}^{-1}$, while the $V_{\max }$ values of control patients ranged from 984 to $1772 \mathrm{mg} \mathrm{h}^{-1}$ (see Table 2). The pharmacokinetic data of the six control patients were comparable to data from literature (Port et al, 1991; Terret et al, 2000)

The effect of the impaired renal function of the index patient on 5 -FU clearance was studied by pharmacokinetic modelling.

The excretion of 5-FU in urine was measured in five patients and $k_{\text {urine }}$ was estimated $0.5 \pm 0.08 \mathrm{~h}^{-1}$. This $\mathrm{k}_{\text {urine }}$ value, individually normalised on calculated GFR, was used during subsequent modelling of other patient data. A normal renal function was simulated in the index patient by replacing the GFR related $\mathrm{k}_{\text {urine }}$ by $\mathrm{k}_{\text {urine }}=0.6$.

Renal function impairment appeared to have only a slight effect on 5-FU clearance. In the index patient, we estimated an additional $18 \%$ increase of the AUC due to the renal insufficiency upon a $108 \%$ higher AUC due to partial DPD deficiency.

Simulation of anuria in the control group $\left(K_{\text {urine }}=0\right)$, revealed a $16 \pm 4 \%$ increase of the 5 -FU AUC.

\section{Activity of DPD in PBM cells}

The activity of DPD in peripheral blood mononuclear (PBM) cells was lower in the patient experiencing severe toxicity $\left(5.5 \mathrm{nmol} \mathrm{mg}{ }^{-1} \mathrm{~h}^{-1}\right)$ compared to the six control patients $(8.0-$ $11.7 \mathrm{nmol} \mathrm{mg}{ }^{-1} \mathrm{~h}^{-1}$; mean 9.6) and comparable to obligate heterozygotes (Van Kuilenburg et al, 2000a)

\section{Genomic sequence analysis}

Sequence analysis of the DPYD gene showed that the patient was heterozygous for a $G \rightarrow A$ point mutation in the invariant $G T$ splice donor site (IVS14+1G $>$ A), leading to the skipping of exon 14

Table I Patient characteristics

\begin{tabular}{|c|c|c|}
\hline & $\begin{array}{c}\text { Index } \\
\text { patient }\end{array}$ & $\begin{array}{l}\text { Controls }(n=6) \\
\text { mean } \pm 2 \text { s.d. }\end{array}$ \\
\hline Gender M/F & $\mathrm{F}$ & $4 / 2$ \\
\hline Age (year) & 69 & $64 \pm 12$ \\
\hline Weight (kg) & 73 & $77 \pm 12$ \\
\hline Serum creatinine $\left(\mu \mathrm{mol} \mathrm{I}{ }^{-1}\right)$ & $184^{\mathrm{a}}$ & $81 \pm 30$ \\
\hline Aspartate aminotransferase $\left(\cup I^{-1}\right)$ & 23 & $18 \pm 8$ \\
\hline Alanine aminotransferase $\left(\cup^{-1}\right)$ & 41 & $29 \pm 26$ \\
\hline $\mathrm{LDH}\left(\cup \mathrm{I}^{-1}\right)$ & 379 & $302 \pm 152$ \\
\hline Alkaline phosphatase $\left(\left.\cup\right|^{-1}\right)$ & 95 & $72 \pm 24$ \\
\hline Bilirubin total $\left(\mu \mathrm{mol} \mathrm{I}^{-1}\right)$ & 7 & $10 \pm 6$ \\
\hline Albumin $\left(\mathrm{gl}^{-1}\right)$ & 32 & $37 \pm 8$ \\
\hline
\end{tabular}

${ }^{a}$ Outside $95 \%$ control range, $P<0.05$. 


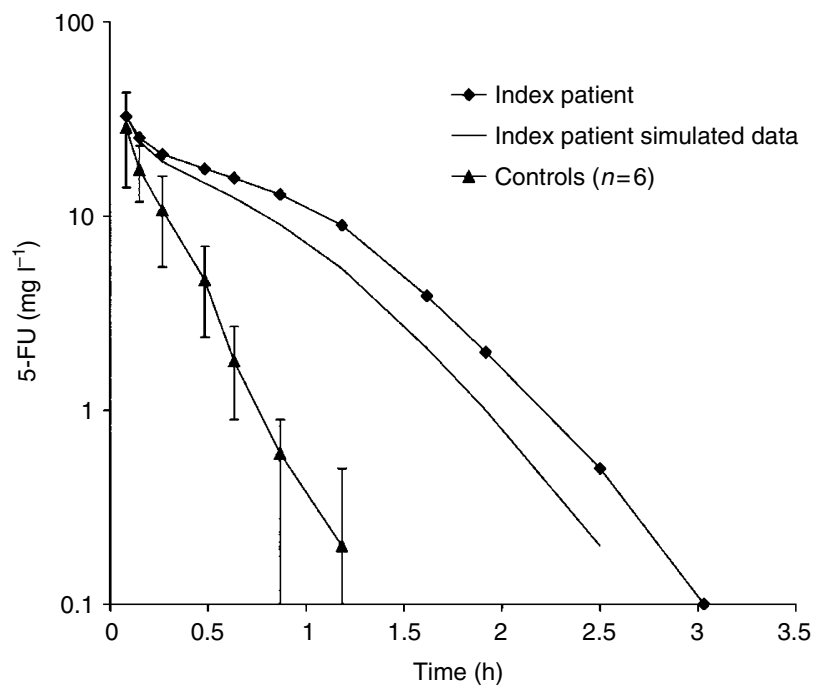

Figure 2 Pharmacokinetics of 5-FU. Shown are 5-FU plasma levels observed in a patient with a IVSI4+IG>A mutation in the DPYD gene (solid diamond) and the 5-FU plasma levels resulting from simulation of a normal renal function in the same patient. 5-FU plasma levels from control patients are depicted as mean \pm s.d. (solid triangle; $n=6$ ).

Table 2 Overview of pharmacokinetic parameters. Data are presented as single observation or as mean \pm 2 s.d.

\begin{tabular}{lcccc}
\hline & $\begin{array}{c}\text { Index patient } \\
\text { patient }\end{array}$ & $\begin{array}{c}\text { Index } \\
\mathbf{K}_{\text {urine }}=\mathbf{0 . 6} \\
\text { simulated } \\
\text { data }\end{array}$ & $\begin{array}{c}\text { Controls } \\
(\boldsymbol{n = 6})\end{array}$ & $\begin{array}{c}\text { Controls } \\
\mathbf{K}_{\text {urine }}=\mathbf{0} \\
\text { simulated } \\
\text { data }\end{array}$ \\
\hline Dose $\left(\mathrm{mg} \mathrm{m}^{-2}\right)$ & 447 & & $431 \pm 64$ & \\
AUC 5-FU $\left(\mathrm{mg} \mathrm{h}^{-1}\right)$ & $24.1^{\mathrm{a}}$ & $20.4^{\mathrm{a}}$ & $10.0 \pm 6.6^{\mathrm{a}}$ & $11.8 \pm 8.6^{\mathrm{a}}$ \\
$\mathrm{Cl} \mathrm{5-FU}\left(\mathrm{ml} \mathrm{min}^{-1}\right)$ & $553^{\mathrm{a}}$ & $637^{\mathrm{a}}$ & $1493 \pm 840^{\mathrm{a}}$ & $1306 \pm 886$ \\
$V_{\max }\left(\mathrm{h}^{-1}\right)$ & $548^{\mathrm{a}}$ & & $1329 \pm 680^{\mathrm{a}}$ & \\
$V_{1} \mathrm{~kg}^{-1}(\mathrm{l})$ & 0.25 & & $0.23 \pm 0.06$ & \\
$K_{12}\left(\mathrm{~h}^{-1}\right)$ & 9.0 & & $5.1 \pm 7.6$ & \\
$K_{21}\left(\mathrm{~h}^{-1}\right)$ & 7.5 & & $5.2 \pm 6.6$ & \\
\hline
\end{tabular}

${ }^{a}$ Data of index patient outside $95 \%$ control range, $P<0.05$.

directly upstream of the mutated splice donor site during DPD pre-mRNA splicing.

Sequence analysis of exon 14 of DPYD of the six control patients revealed no mutations.

\section{DISCUSSION}

5-Fluorouracil remains the major drug in the treatment of advanced colorectal cancer. Dihydropyrimide dehydrogenase is the key metabolic enzyme in 5-FU degradation and since more than $80 \%$ of the dose is metabolised by this enzyme, DPD activity is one of the main factors determining drug exposure (Harris et al, 1990; Fleming et al, 1992a; Lu et al, 1993; Etienne et al, 1994). It is generally accepted that DPD activity in the liver is responsible for the majority of 5-FU catabolism (Ho et al, 1986; Fleming et al, 1992b), but PBM cells are often used as a surrogate for liver DPD activity, since these cells are better accessible (Harris et al, 1990; Fleming et al, 1992a; Lu et al, 1993; Etienne et al, 1994). Several groups have suggested that markedly diminished DPD activity in PBM cells is strongly related to the risk of developing severe 5-FU toxicity due to reduced 5-FU clearance ( $\mathrm{Lu}$ et al, 1993; Etienne et al, 1994; Van Kuilenburg et al, 2000a). Although total DPD deficiency is rare in adults, about $2-3 \%$ of the popula- tion has a low PBM-DPD enzyme level and, thus, is at risk to develop severe toxicity when treated with 5-FU (Etienne et al, 1994; Lu et al, 1995; Chazal et al, 1996). In only few reports however, the effect of DPD-deficiency on 5-FU clearance has been objectively quantified. Diasio et al (1988) administered a test dose of $25 \mathrm{mg} \mathrm{m}^{-2} 5$-FU to a patient with non-detectable DPD-activity in PBM cells and found a very low 5-FU clearance rate. This patient was probably homozygous for a mutant DPD allele, although the genetic cause was never elucidated. Stephan et al (1995) reported severe toxicity in a female patient after treatment comprising Leuvorin $500 \mathrm{mg} \mathrm{m}^{-2}$ as $2 \mathrm{~h}$ intravenous infusion plus $125 \mathrm{mg}$ orally, followed by $5-\mathrm{FU} 2 \mathrm{~g} \mathrm{~m}^{-2}$ as a $24 \mathrm{~h}$ continuous infusion. They found a 5 -FU plasma level of $0.3 \mathrm{mg} \mathrm{l}^{-1}$ on day 15 after administration, which implies a dramatic overexposure to 5-FU. This patient could not have been homozygous deficient because the DPD activity in lymphocytes was within the normal range. The role of PBM-DPD activity as an indicator for 5-FU clearance is, however, questionable. Lu et al (1993) found a correlation between PBM - DPD activity and DPD activity measured in the liver, but others reported a weak, non-significant relationship (Chazal et al, 1996). Both Harris et al (1990) and Fleming et al (1992a) initially reported a correlation between PBM-DPD activity and 5-FU clearance but re-examination of this relationship in a larger set of patients revealed a markedly weakened correlation (Etienne et al, 1994). These data indicate that PBM-DPD activity is not a strong and reliable indicator of 5-FU clearance. To some extent, the variability in DPD activity might have been caused by the composition of the isolated PBM cells (Van Kuilenburg et al, 2000b). Another important factor is the timing of cell sampling in relation to 5-FU administration, since McLeod et al (1998) showed that $5-\mathrm{FU}$ is able to inhibit DPD-activity.

In this paper, we report a combined pharmacokinetic and genetic analysis of the DPYD gene and demonstrate that a single $G \rightarrow A$ point mutation in the invariant splice donor site IVS14+1 of the DPYD gene has profound impact on the clearance of 5-FU. We also found a lower PBM-DPD activity in the index patient compared to six controls. The DPD activity was comparable to the activity observed in obligate heterozygotes $\left(5.5 \pm 2.1 \mathrm{nmol} \mathrm{mg}{ }^{-1} \mathrm{~h}^{-1}, n=8\right)$ in previous work (Van Kuilenburg et al, 2000a), but the measured value also fits within the range for normal controls $\left(10.0 \pm 3.4 \mathrm{nmol} \mathrm{mg}^{-1} \mathrm{~h}^{-1}\right.$, range $3.4-18 \mathrm{nmol} \mathrm{mg}{ }^{-1} \mathrm{~h}^{-1}, n=22$ ). This might indicate that not only obligate heterozygotes, but also low normal homozygotes are at risk for developing severe toxicity when treated with 5-FU. It is however as yet unclear whether the pharmacokinetic profile of 5FU is identical in both groups.

We did not measure DPD activity and 5-FU pharmacokinetics on the same day. DPD activity was measured at least 2 months after completing chemotherapy and therefore might have been changed since the first chemotherapy cycle as a result of chemotherapy itself or disease state. Although 5-FU has a direct inhibitory effect on DPD activity, as was shown by McLeod et al (1998), we believe that it is not likely that this effect will continue until 2 months after the last dose. Furthermore, it has been shown that DPD activity is lower in breast-cancer patients compared to healthy persons (Lu et al, 1998), suggesting an effect of disease state on DPD activity. All our patients had Dukes C carcinoma and showed no signs of disease progression at the time of blood sampling for DPD. Therefore we considered the index patient and controls comparable regarding their disease state. Thus, despite delayed DPD sample collection, we believe our results to be representative for DPD activity during pharmacokinetic sampling.

The structural organization of the DPYD gene has recently been described. It is $150 \mathrm{~kb}$ in length and consists of 23 exons ranging in size from 69 to $1404 \mathrm{bp}$ (Johnson et al, 1997). The $\mathrm{G} \rightarrow \mathrm{A}$ mutation changes an invariant GT splice donor site into AT which leads to skipping of a $165 \mathrm{bp}$ exon immediately upstream of the mutated spice donor site during the splicing of DPD pre-mRNA. As a 
consequence, a 165 bp fragment encoding the amino acid residues $581-635$ of the primary sequence of the DPD protein is lacking in the mature DPD mRNA, which results in an enzyme without catalytic activity (Wei et al, 1996; Van Kuilenburg et al, 1997). Analysis of the prevalence of the various mutations among cancer patients with partial DPD deficiency showed that the $G \rightarrow A$ mutation in the invariant splice donor site is the most common one $(43 \%)$ (Van Kuilenburg et al, 2000a). The prevalence of this mutation in the normal Dutch population is $1.8 \%$ (Van Kuilenburg et al, 2001).

We believe that in our patient the IVS14+1G $>$ A mutation explains the dramatic reduction in 5-FU clearance compared to controls. This is in line with the observation that at least $80 \%$ of the 5-FU dose is catabolised by DPD. Although our patient had a moderately impaired renal function, we analysed that the effect of renal function on 5-FU clearance is only limited. This was to be expected, as only about $10 \%$ of the 5 -FU dose is normally excreted in urine (Heggie et al, 1987). It is important, however, to realise that in patients with reduced DPD capacity, the contribution of renal excretion to total clearance is relatively increased. As a consequence, the impact of renal insufficiency on the AUC is larger in DPD deficient than in normal patients. Thus, in the index patient, the impaired renal function might have contributed to development of more severe toxicity, additionally to that caused by DPD deficiency.

Development of rapid assays to detect mutations in the DPYD gene makes it possible to carry out a genetic screening prior to the start of chemotherapy containing 5-FU. However, it is important to identify those mutations that result in a defect DPD protein. So far, 19 molecular defects in the DPYD gene such as point mutations and deletions due to exon skipping have been reported, but not all mutations result in a DPD enzyme deficiency (Van Kuilenburg et al, 2000a). Incomplete correlation between DPD phenotype and genotype is clinically important and suggests that DPD polymorphisms are likely to be complex (Collie-Duguid et al, 2000).

Our results indicate that low DPD activity, due to the inactivation of one DPYD allele results in a strong reduction in 5-FU clearance, measured on the first chemotherapy day. Inhibition of the yet reduced DPD activity by 5 -FU itself during subsequent days may lead to further reduction of 5-FU clearance and this may further add to the development of severe toxicity. In order to identify those mutations that result in reduced 5-FU clearance, monitoring of 5-FU plasma levels using a limited sampling strategy can be helpful in patient selection. This requires, however, rapid plasma level analysis, because results from the first 5-FU infusion must be available before the second dose is administered. Unfortunately, no rapid 5-FU (immuno-)assay is available yet, and therefore in most hospitals therapeutic drug monitoring of 5-FU is not yet feasible.

\section{ACKNOWLEDGEMENTS}

We thank Dr JH Proost (Department of Pharmacokinetics and Drug Delivery, State University Groningen) for advice on pharmacokinetic modelling. We thank Roche Basel for providing dihydrofluorouracil chemical standard.

\section{REFERENCES}

Ackland SP, Garg MB, Dunstan RH (1997) Simultaneous determination of dihydrofluorouracil and 5-fluorouracil in plasma by high-performance liquid chromatography. Anal Biochem 246: 79-85

Chazal M, Etienne MC, Renee N, Bourgeon A, Richelme H, Milano G (1996) Link between dihydropyrimidine dehydrogenase activity in peripheral blood mononuclear cells and liver. Clin Cancer Res 2: 506-510

Collie-Duguid ES, Etienne MC, Milano G, McLeod HL (2000) Known variant DPYD alleles do not explain DPD deficiency in cancer patients. Pharmacogenetics 10: $217-223$

Diasio RB, Beavers TL, Carpenter JT (1988) Familial deficiency of dihydropyrimine dehydrogenase. Biochemical basis for familial pyrimidinemia and severe 5-fluorouracil induced toxicity. J Clin Invest 81: 47-51

Etienne MC, Lagrange JL, Dassonville O, Fleming R, Thyss A, Renee N, Schneider M, Demard F, Milano G (1994) Population study of dihydropyrimidine dehydrogenase in cancer patients. J Clin Oncol 12: 2248-2253

Fleming RA, Milano G, Thyss A, Etienne MC, Renee N, Schneider M, Demard F (1992a) Correlation between dihydropyrimidine dehydrogenase activity in peripheral mononuclear cells and systemic clearance of fluorouracil in cancer patients. Cancer Res 52: 2899-2902

Fleming RA, Milano GA, Etienne MC, Renee N, Thyss A, Schneider M, Demard F (1992b) No effect of dose, hepatic function, or nutrional status on 5-FU clearance following continuous (5-day) 5-FU infusion. $\mathrm{Br} \mathrm{J}$ Cancer 66: $668-672$

Harris BE, Song R, Soong SJ, Diasio RB (1990) Relationship between dihydropyrimidine dehydrogenase activity and plasma 5-fluorouracil levels with evidence for circadian variation of enzyme activity and plasma drug levels in cancer patients receiving 5-fluorouracil by protracted continuous infusion. Cancer Res 50: $197-201$

Heggie GD, Sommadosi JP, Cross DS, Huster WJ, Diasio RB (1987) Clinical pharmacokinetics of 5-fluorouracil and its metabolites in plasma, urine and bile. Cancer Res 47: 2203-2206

Ho DH, Townsend L, Luna M, Bodey GP (1986) Distribution and inhibition of dihydrouracil dehydrogenase activities in human tissues using 5-fluorouracil as substrate. Anticancer Res 6: 781-784

Johnson MR, Wang K, Tillmanns S, Albin N, Diasio RB (1997) Structural organization of the human dihydropyrimidine dehydrogenase gene. C. ancer Res 57: $1660-1663$
Lu Z, Zhang R, Diasio RB (1993) Dihydropyrimine dehydrogenase activity in human peripheral blood mononuclear cells and liver: population characteristics, newly identified patients, and clinical implication in 5fluorouracil chemotherapy. Cancer Res 53: 5433-5438

Lu Z, Zhang R, Diasio RB (1995) Population characteristics of hepatic dihydropyrimidine dehydrogenase activity, a key metabolic enzyme in 5fluorouracil chemotherapy. Clin Pharmacol Ther 58: 512-522

Lu Z, Zhang R, Carpenter JT, Diasio RB (1998) Decreased dihydropyrimine dehydrogenase activity in a population of patients with breast cancer: implication for 5-fluorouracil-based chemotherapy. Clin Cancer Res 4: $325-329$

McLeod HL, Sludden J, Hardy SC, Lock RE, Hawksworth GM, Cassidy J (1998) Autoregulation of 5-fluorouracil metabolism. Eur J Cancer 34: $1623-1627$

Pinedo HM, Peters GF (1988) Fluorouracil: biochemistry and pharmacology. J Clin Oncol 6: $1653-1664$

Port RE, Edler L, Herrmann R, Feldmann U (1991) Pharmacokinetics of 5 fluorouracil after short systemic infusion: plasma level at the end of the distribution phase as an indicator of the total area under the plasma concentration - time curve. Ther Drug Mon 13: 96-102

Smith PK, Krohn RI, Hermanson GT, Mallia AK, Gartner FH, Provenzano MD, Fujimoto EK, Goeke NM, Olson BJ, Klenk DC (1985) Measurement of protein using bicinchoninic acid. Anal Biochem 150: 76-85

Stephan F, Etienne MC, Wallays C, Milano G, Clergue F (1995) Depressed hepatic dihydropyrimidine dehydrogenase activity and fluorouracil related toxicities. Am J Med 99: 685-688

Terret C, Erdociain E, Guimbaud R, Boisdron-Celle M, McLeod HL, FetyDeporte R, Lafond T, Gamelin E, Bugat R, Canal P, Chatelut E (2000) Dose and time dependencies of 5-fluorouracil pharmacokinetics. Clin Pharmacol Ther 68: $270-279$

Van Kuilenburg ABP, Vreken P, Beex LV, Meinsma R, Van Lenthe H, DeAbreu RA, Van Gennip AH (1997) Heterozygosity for a point mutation in an invariant splice donor site of dihydropyrimine dehydrogenase and severe 5-fluorouracil related toxicity. Eur J Cancer 33: 2258-2264 
Van Kuilenburg ABP, Haasjes J, Richel DJ, Zoetekouw L, Van Lenthe $\mathrm{H}$, Waterham HR, De Abreu RA, Maring JG, Vreken P, Van Gennip AH (2000a) Clinical implications of dihydropyrimidine dehydrogenase (DPD) deficiency in patients with severe 5-fluorouracil associated toxicity. Identification of new mutations in the DPD gene. Clin Cancer Res 6: $4705-4712$

Van Kuilenburg ABP, Van Lenthe H, Tromp A, Veldman PC, Van Gennip AH (2000b) Pitfalls in the diagnosis of patients with partial dihydropyrimidine dehydrogenase deficiency. Clin Chem 46: 9-17
Van Kuilenburg ABP, Muller EW, Haasjes J, Meinsma R, Zoetekouw L, Waterham HR, Baas F, Richel DJ, Van Gennip AH (2001) Lethal outcome of a patient with complete dihydropyrimidine dehydrogenase (DPD) deficiency after administration of 5-fluorouracil: frequency of the common IVS14+1G > A mutation causing DPD deficiency. Clin Cancer Res 7: $1149-1153$

Wei X, McLeod HL, McMurrough J, Gonzalez FJ, Fernandez-Salguero P (1996) Molecular basis of the human dihydropyrimidine dehydrogenase deficiency and 5-fluorouracil toxicity. J Clin Invest 98: 610-615 